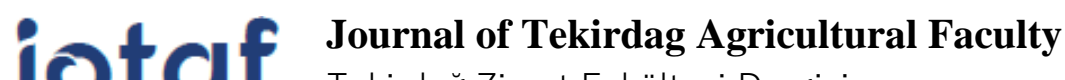

\section{Jeoistatistiksel Modelleme ile Edirne İli Uzunköprü İlçesi Topraklarının Bazı Mikro Element Düzeylerinin Haritalanması}

\author{
Mapping of Some Micro Element Levels with Geostatistical Modeling in Uzunköprü District \\ of Edirne Province
}

\author{
Yakup Kenan KOCA ${ }^{*}$, Ali DERİN², Sevinç ADİLOĞLU ${ }^{2}$
}

\section{$\ddot{O} z$}

Bitki gelişimi için makro besin elementleri kadar önemli olan mikro besin elementlerinin toprakta yeter düzeyde bulunmayışı, verim ve ürün kalite özelliklerine olumsuz etkide bulunmaktadır. Toprakta bulunma düzeyleri makro besin elementlerine göre nispeten daha düşük olan demir, bakır, mangan ve çinko mikro besin elementleri olarak adlandırmaktadır. Yapılan çalışmalarda bu besin elementlerinin noksanlığı durumunda bitkide çeşitli simptomlar meydana geldiği bildirilmektedir. Bu çalışma ile Edirne ili Uzunköprü ilçesi topraklarının kimi mikro besin elementi düzeyleri ortaya konmuştur. Bu kapsamda İlçe topraklarını temsil edecek düzeyde yeter sayıda toprak örneklemesi yapılmış; sonuçlar jeoistatistiksel modelleme yardımıyla tüm alan için haritalanmıştır. İlçe topraklarında tamamında bakır yeter düzeyde iken, demir orta ve yüksek düzeylerde, mangan az ve yeter düzeylerde bulunmuştur. Çinko ise Türkiye toprakları ile benzerlik göstermekte olup; çalışma alanının önemli bir kısmında kritik düzeyin altındadır.

Anahtar kelimeler: Toprak, Mikro element, Edirne, Jeoistatistik, Dağılım haritası

\begin{abstract}
Micro nutrients, which are as important as the macro nutrients for plant development, are not sufficient in soil and consequently have a negative effect on yield and product quality characteristics. Iron, copper, manganese and zinc are called micro nutrients which are relatively lower than the levels of macro nutrients. In the studies conducted in the deficiency of these nutrients in the plant has been reported to have various symptoms. In this study, some micronutrient element levels of Uzunköprü district of Edirne province were revealed. In this study, a sufficient number of soil samples were sampled at the level to represent the study area; results are mapped to the all study area with the help of geostatistical modeling. In the soil, copper was at a sufficient level, while iron was found to be medium and high and manganese at low and high levels. Zinc is similar to the Turkey's soil; a significant portion of the study area is below the critical level.
\end{abstract}

Keywords: Soil, Micro element, Edirne, Geostatistical, Distribution map

\footnotetext{
1*Sorumlu Yazar/Corresponding Author: Yakup Kenan Koca, Dicle Üniversitesi, Ziraat Fakültesi, Toprak Bilimi ve Bitki Besleme Bölümü, Diyarbakır Email: ykkoca@dicle.edu.tr (iD) OrcID: 0000-0001-9285-1416

${ }^{2}$ Ali DERIN, Tekirdağ Namık Kemal Üniversitesi, Ziraat Fakültesi, Toprak Bilimi ve Bitki Besleme Bölümü, Tekirdağ. E-mail: ali-derin@windowslive.com OrcID: 0000-0002-0516-0711

${ }^{2}$ Sevinç ADİLOĞLU Tekirdağ Namık Kemal Üniversitesi, Ziraat Fakültesi, Toprak Bilimi ve Bitki Besleme Bölümü, Tekirdağ.. E-mail: sadiloglu@nku.edu.tr, (iD OrcID: 0000-0002-0062-0491

Atıf/Citation: Koca Y., K., Derin A, Adiloğlu S. Jeoistatistiksel Modelleme ile Edirne İli Uzunköprü İlçesi Topraklarının Bazı Mikro Element Düzeylerinin Haritalanmas1, Tekirdağ Ziraat Fakültesi Dergisi, 16(3), 328-338
} 


\section{Extendend Summary}

Nutrient elements, which are called micronutrients, are as important as plant nutrients because they are used less by plants. Iron $(\mathrm{Fe})$, Copper $(\mathrm{Cu})$, Manganese $(\mathrm{Mn})$ and Zinc $(\mathrm{Zn})$ are some of the important micronutrients. Micronutrients which are as important as macro nutrients are necessary to show the situation in terms of the sustainability of soil fertility and to take the necessary importance against this situation. On the other hand, it depends on the availability and availability of micro-plant nutrients which are sufficient and balanced in soil for healthy plant production. Micro nutrients, which are as important as the macro nutrients for plant development, are not sufficient in soil and consequently have a negative effect on yield and product quality characteristics. In the studies conducted in the deficiency of these nutrients in the plant has been reported to have various symptoms.

In this study, some microelement levels were investigated by geostatistical modeling of Uzunköprü districts of Edirne province. In the study, copper $(\mathrm{Cu})$, Iron $(\mathrm{Fe})$, Mangan $(\mathrm{Mn})$ and Zinc $(\mathrm{Zn})$ values were determined from soil samples taken from 25 points determined from Uzunköprü district of Edirne province. For this purpose, coordinates were determined by using the hand GPS while sampling from the determined points. Surface soil samples were taken from the villages of Hamitli, Kurtbey, Kadikoy, Cakmak, Çöpköy, Ömerbey, Yeniköy, Kavacık, Karapınar and Türkobası. The soil samples were extracted with $0.005 \mathrm{M}$ DTPA+ $0.01 \mathrm{M} \mathrm{CaCl}_{2}+0.1 \mathrm{M}$ TEA (pH 7.3) for useful micro-element analysis.

The amounts of $\mathrm{Fe}, \mathrm{Cu}, \mathrm{Zn}$ and $\mathrm{Mn}$ in the extract were determined in the ICP-OES device. Spatial distributions of point data were determined by geostatistical modeling. For this purpose, spatial distribution maps of micronutrient elements were created by using Inverse Distance Weighted (IDW) interpolation modeling which was determined to be the most suitable data in ArcMAP 10.2 software.

It was observed that sufficient copper was present in all of the soils. The lowest copper level was determined in the example 13 with $0.53 \mathrm{mg} \mathrm{kg}^{-1}$, while the highest copper level was determined in the example point 8 with $3.28 \mathrm{mg} \mathrm{kg}^{-1}$. It was observed that sufficient copper was present in all of the soils. The lowest copper level was determined in the example point 13 with $0.53 \mathrm{mg} \mathrm{kg}^{-1}$, while the highest copper level was determined in the example point 8 with $3.28 \mathrm{mg} \mathrm{kg}$. The amount of iron in the soil samples ranged from 6.76 to $76.58 \mathrm{mg} \mathrm{kg}^{-1}$. These results indicate that the region is rich in iron levels. The average iron level of $21.38 \mathrm{mg} \mathrm{kg}^{-1}$ is higher than many studies. The manganese level of the study area varies between 2.43 and $77.12 \mathrm{mg} \mathrm{kg}^{-1} .52 \%$ of the soil samples taken and $40 \%$ of them have enough Mn content. Zinc levels in the soil samples taken within the scope of the study ranged from 0.12 to $1.44 \mathrm{mg} \mathrm{kg}^{-1}$, and are generally below the critical level. In conclusion, geostatistical modeling and distribution maps were obtained by using the data obtained from the point data to reveal a general situation of the microelement of the study area. 

elementleri bitki gelişimi için en az makro besin elementleri kadar önemlidir. Demir (Fe), Bakır ( $\mathrm{Cu}$ ), Mangan (Mn) ve Çinko (Zn) önemli mikro besin elementlerinden birkaçıdır. Bu besin elementinin toprakta yeter düzeyde bulunmaması bitkide çeşitli belirtilere de yol açmaktadır. Bununla birlikte mikro besin elementlerinin topraklarda yeter düzeyde bulunmaması elde edilen üründe verim ve kaliteye de olumsuz etkilere sebep olmaktadır.

Sürdürülebilir tarım için en önemli etkenlerden biri toprak verimliliğidir. Toprağın verimliliğinde de en önemli husus, topraktaki bitki besin elementlerinin bitkilere yarayışlı ve elverişli miktarlarının en hassas ve doğru bir şekilde belirlenmesidir. Verimli toprak irdelendiğinde bir yandan bitki besin elementleri bitkilerde yeterli miktarlarda ve dengeli oranlarda diğer yandan bitki kök bölgesinde de alınabilir düzeyde bulunması gerekmektedir. Makro besin elementleri kadar önemli olan mikro besin elementleri toprak verimliliğinin sürdürülebilirliği açısından var olan durumun ortaya konması ve bu durum karşısında da gerekli önemlerin alınması gereklidir. Diğer taraftan sağlıklı bitkisel üretim için toprakta yeterli ve dengeli düzeyde bulunan mikro bitki besin elementlerinin varlığına ve alınabilirliğine bağlıdır.

Bu çalışmada Edirne İli Uzunköprü ilçesi topraklarının jeoistatistiksel modelleme ile bazı mikro element düzeyleri ortaya konulmaya çalışılmıştır.

\section{Materyal ve Yöntem}

$\mathrm{Bu}$ çalışma ile Edirne İli Uzunköprü İlçesi topraklarının mikro element düzeyleri ele alınmıştır. Dünyanın en uzun taş köprüsüne sahip olması ile turizm açısından da önemli bir değere sahip olan İlçe, Türkiye'nin en batı sınırındaki ilçelerden birisidir (Şekil 1). Önemli tarım potansiyeline sahip bölgede bulunan Ergene Havzası'ndan dolayı tarım ve tarımsal sanayi önemli ekonomik faaliyetlerdendir. En önemli faaliyetler tarım, hayvancılık ve seracılıktır (Karbuz, 2016). Bellitürk (2011) tarafından yapılan çalışmada, bölge topraklarının genellikle toprak pH'sının asidik karakterde olduğu, düşük organik madde içeriğine sahip olduğu, azot bakımından fakir, ortalama $\mathrm{P}, \mathrm{Ca}, \mathrm{Mg}, \mathrm{Fe}, \mathrm{Mn}, \mathrm{Cu}$ içerikleri bakımından yeterli, $\mathrm{K}$ ve $\mathrm{Zn}$ içeriği bakımından da yetersiz olduğu belirtilmiştir.

Çalışmada Edirne ili Uzunköprü ilçesinden tesadüfi olarak belirlenen 25 noktadan (Şekil 1) alınan toprak örneklerinde Bakır (Cu), Demir (Fe), Mangan ( $\mathrm{Mn}$ ) ve Çinko ( $\mathrm{Zn}$ ) değerleri belirlenmiş̧ir. Bu amaçla belirlenen noktalardan örneklemeler yapılırken el GPS'i kullanılarak koordinat okuması yapılmışıı. Çalışma alanı olarak belirlenen Uzunköprü ilçesinin Hamitli, Kurtbey, Kadıköy, Çakmak, Çöpköy, Ömerbey, Yeniköy, Kavacık, Karapınar ve Türkobası köylerinden 0-30 cm derinlikten toprak örnekleri alınmıştır. Toprak örneklerini yarayışlı mikro element analizi için $0.005 \mathrm{M} \mathrm{DTPA}+0.01 \mathrm{M} \mathrm{CaCl} 2+0.1 \mathrm{M}$ TEA (pH 7.3) ile ekstrakte edilmiştir (Lindsay ve Norvell 1978). Ekstraktaki yarayışlı $\mathrm{Fe}, \mathrm{Cu}, \mathrm{Zn}$ ve Mn miktarları ICP-OES cihazında tespit edilmiştir. Jeoistatistiksel modelleme ile noktasal verilerin alansal dağılımları belirlenmiştir. Bu amaçla ArcMAP 10.2 yazılımda yeralan ve verilere en uygun olduğu belirlenen Inverse Distance Weighted (IDW) interpolasyon modellemesi kullanılarak mikro besin elementlerin ilçe düzeyinde alansal dağılım haritaları oluşturulmuştur. 


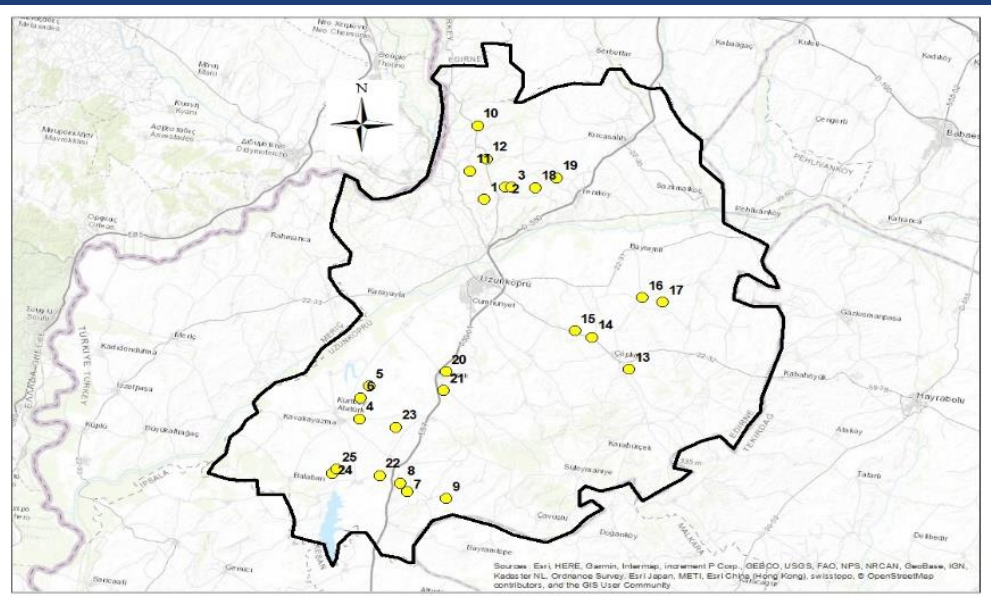

Şekil 1. Çalışma alanı Uzunköprü ilçesi ve örnekleme noktaları

Figure 1.. Study Area Uzunköprü District and sampling point

\section{Bulgular}

Örnekleme yapılan noktalardan alınan toprak örneklerinde $\mathrm{Cu}$, Fe, Mn ve $\mathrm{Zn}$ düzeyleri belirlenmiş ve Çizelge 1 'de gösterilmiştir.

Bakır (Cu): Tarım topraklarında 1-50 mg kg-1 arasında değişmektedir (Kacar ve Katkat, 2007). Ancak topraklardaki toplam bakır içerikleri ile yarayışlı bakır içerikleri arasında bir ilgi bulunmamaktadır. Eyüpoğlu ve ark. (1996) tarafından yapılan çalışmada, Türkiye topraklarını temsilen alınan 1511 toprak örneğinin tamamında $\mathrm{Cu}$ için kritik düzey olarak belirtilen $0.2 \mathrm{mg} \mathrm{kg}^{-1}$ 'in üzerinde bulunmuştur. Bu çalışma kapsamında alınan 25 toprak örneğinde ise benzer bir durumla karşılaşılmış ve toprakların tamamında yeter düzeyde Cu'nun mevcut olduğu görülmüştür. En düşük bakır düzeyi $0.53 \mathrm{mg} \mathrm{kg}^{-1}$ ile 13 numaralı örnekte belirlenir iken en yüksek Cu düzeyi ise $3.28 \mathrm{mg} \mathrm{kg}^{-1}$ ile 8 numaralı örnekte tespit edilmiştir. 25 örnek ortalamasına bakıldığında elde edilen değer Güneş ve ark. (1996) tarafından yapılan çalışma ile benzerlik göstermektedir.

Demir (Fe): Diğer mikro bitki besin elementlerine göre topraklarda genellikle daha fazla bulunmakta olan demir, önemli bir bitki besin elementidir. Topraklarda toplam Fe düzeyinin fazla olmasına karşın bitkiler tarafından alınabilir miktarı genellikle düşüktür (Kacar ve Katkat, 2007). Topraklarda Fe düzeyi $0.2 \mathrm{mg} \mathrm{kg}^{-1} \mathrm{dan}$ daha düşük düzeyde ise az; 0.2-4.5 $\mathrm{mg} \mathrm{kg}^{-1}$ düzeyinde ise orta ve $4.5 \mathrm{mg} \mathrm{kg}^{-1}$ düzeyinden daha yüksek ise fazla olarak değerlendirilmektedir. Çalışma kapsamında alınan toprak örneklerinde Fe miktarı 6.76 ile $76.58 \mathrm{mg} \mathrm{kg}^{-1}$ arasında değiştiği görülmüştür. Eyüpoğlu ve ark. (1996) tarafından yapılan çalışmada Türkiye topraklarının Fe içeriği genellikle orta ve yüksek olarak belirlenmiştir. Çalışma kapsamında alınan toprak örneklerinde en düşük Fe düzeyi 13 numaralı örnekte, en yüksek Fe düzeyi ise 15 numaralı örnekte belirlenmiştir. Bu sonuçlar bölge topraklarının Fe düzeyi bakımından zengin olduğunu göstermektedir. Ortalama $21.38 \mathrm{mg} \mathrm{kg}^{-1}$ düzeyinde bulunan Fe, birçok çalışmaya göre yüksek düzeydedir. Bunun en büyük sebebi ise toprakların genellikle asidik pH'ya sahip olmasından ileri gelmektedir. Nitekim kireçli topraklara göre asit topraklarda daha fazla çözünebilir inorganik Fe bulunmaktadır (Güneş ve ark., 2013). Toprakların genel özelliklerine bakıldığında daha net bir sonuç elde edilmiştir. En düşük Fe düzeyine sahip toprakların genellikle kireç düzeyinin yüksek olduğu; buna karşın yüksek 

Fe içeriğine sahip toprakların ise kireçsiz olduğu belirlenmiştir. Bu konuda bölgede daha önce yapılan çalışmalar ile araştırma bulguları uygunluk içerisindedir (Adiloğlu, 2010).

Çizelge 1. Toprak örneklerinin ekstrakte edilebilir metal içerikleri, $\mathrm{mg} \mathrm{kg}^{-1}$

Table 1. Extractable metal contents of soil samples, $\mathrm{mg} \mathrm{kg}^{-1}$

\begin{tabular}{|c|c|c|c|c|}
\hline Örnek No & $\mathrm{Cu}$ & $\mathrm{Fe}$ & $\mathrm{Mn}$ & $\mathrm{Zn}$ \\
\hline 1 & 1.22 & 10.25 & 17.63 & 0.15 \\
\hline 2 & 1.36 & 41.90 & 29.30 & 0.30 \\
\hline 3 & 2.36 & 18.98 & 26.20 & 0.42 \\
\hline 4 & 1.15 & 9.37 & 11.34 & 0.16 \\
\hline 5 & 3.20 & 10.37 & 4.85 & 0.15 \\
\hline 6 & 2.20 & 18.30 & 22.31 & 0.58 \\
\hline 7 & 1.53 & 11.83 & 8.92 & 0.19 \\
\hline 8 & 3.28 & 21.20 & 9.44 & 0.25 \\
\hline 9 & 1.08 & 11.40 & 6.74 & 0.22 \\
\hline 10 & 1.72 & 28.08 & 43.73 & 0.26 \\
\hline 11 & 1.25 & 11.35 & 14.05 & 0.31 \\
\hline 12 & 1.37 & 11.76 & 13.81 & 0.33 \\
\hline 13 & 0.53 & 6.76 & 5.68 & 0.20 \\
\hline 14 & 0.92 & 47.00 & 14.79 & 1.44 \\
\hline 15 & 0.86 & 76.58 & 38.66 & 0.60 \\
\hline 16 & 0.92 & 7.57 & 9.33 & 0.27 \\
\hline 17 & 1.93 & 16.01 & 7.64 & 0.44 \\
\hline 18 & 2.44 & 36.09 & 39.67 & 0.71 \\
\hline 19 & 1.29 & 16.36 & 10.27 & 0.31 \\
\hline 20 & 0.85 & 9.02 & 10.96 & 0.32 \\
\hline 21 & 1.60 & 15.89 & 2.43 & 0.61 \\
\hline 22 & 1.02 & 10.33 & 7.21 & 0.12 \\
\hline 23 & 1.05 & 11.02 & 7.42 & 0.17 \\
\hline 24 & 1.53 & 24.63 & 38.17 & 0.22 \\
\hline 25 & 1.75 & 52.36 & 77.12 & 0.30 \\
\hline Ort & 1.54 & 21.38 & 19.11 & 0.36 \\
\hline Min & 0.53 & 6.76 & 2.43 & 0.12 \\
\hline Max & 3.28 & 76.58 & 77,12 & 1.44 \\
\hline
\end{tabular}


Mangan (Mn): Toprakların toplam mangan içeriği 20 ile $300 \mathrm{mg} \mathrm{kg}^{-1}$ arasında değişmektedir. Toprakların

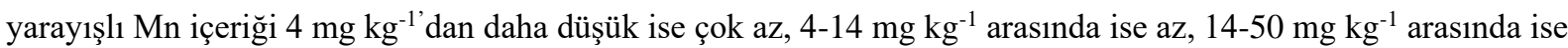
yeter, 50-170 mg kg-1 arasında ise fazla ve $170 \mathrm{mg} \mathrm{kg}^{-1}$ den daha fazla ise çok fazla şeklinde ifade edilmektedir

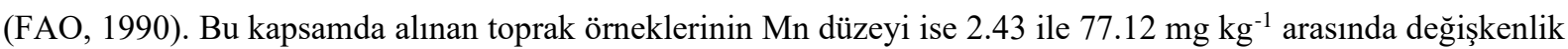
göstermektedir. Bu verilere göre 21 numaralı toprak örneğinin Mn içeriği çok az; 4, 5, 7, 8, 9, 12, 13, 16, 17, 19, 20, 22, 23 numaralı toprak örneklerinin Mn içeriğgi az; 1, 2, 3, 6, 10, 11, 14, 15, 18 ve 24 numaralı toprak örneğinin Mn içeriği yeter ve 25 numaralı toprak örneğinin ise Mn içeriği fazla olarak belirlenmiştir. Alınan toprak örneklerinin \%52’si az ve \%40’1 yeter düzeyde Mn içeriğine sahiptir. Toprakların Mn düzeyine yönelik bulgular Eyüpoğlu ve ark. (1996) tarafından yapılan çalışma ile benzerlik göstermektedir. Toprakların yarayışlı mangan içerikleri ile organik madde miktarları arasındaki negatif ilişki nedeniyle mangan içerikleri çok az ve az sınıfına girmektedir (Kızllgöz ve ark., 2009)

Çinko (Zn): Toprakların toplam Zn miktarları 10-300 $\mathrm{mg} \mathrm{kg}^{-1}$ arasında değişim göstermektedir. Litosferde ise ortalama Zn miktarı $80 \mathrm{mg} \mathrm{kg}^{-1}$ dır (Krauskopf, 1972; Kacar ve Katkat, 2007). Toprakların değişebilir çinko düzeyleri ise 0.1 ile $2 \mathrm{mg} \mathrm{kg}^{-1}$ arasında değişmektedir. Topraklarda kritik değer olarak $0.5 \mathrm{mg} \mathrm{kg}^{-1}$ olarak kabul edilir ve bu düzeyin altındaki $\mathrm{Zn}$ değeri yetersiz olarak tanımlanmaktadır (FAO, 1990). Çalışma kapsamında alınan toprak örneklerinde $\mathrm{Zn}$ düzeyi 0.12 ile $1.44 \mathrm{mg} \mathrm{kg}^{-1}$ arasında değişmekte olup, genellikle Zn kritik düzeyin altındadır. Örneklerden yalnızca 6, 14, 15, 18 ve 21 nolu örnekler kritik düzeyin üzerinde Zn içeriğine sahiptir. Buna göre çalışma alanından alınan örneklerin \%80’1 kritik düzeyin altında Zn içeriğine sahiptir. Nitekim Sillanpaa ve Vlek (1985), Katkat ve ark. (1994), Eyüpoğlu ve ark. (1996), Çakmak ve ark. (1996)'nın çalışmaları Türkiye topraklarının genellikle Zn düzeyinin kritik değerin altında olduğunu belirtmektedir. Araştırma topraklarının yarayışlı çinko içeriklerinin düşük olmasının nedeni olarak toprakların demir içeriklerinin yeterli ve fazla olması bir sebep olarak gösterilebilir (K1zılgöz ve ark., 2011; Adiloğlu ve ark., 2010)

Coğrafik olarak uzaysal konumu belirli olan en az iki noktadan elde edilen verilerin değerlendirilmesi ve/veya ilişkilendirilmesi ile ilgili çalışmalar olarak tanımlanan jeoistatistik bilimi (Webster ve Oliver, 1990), en az iki noktadan elde edilen verilerin istatistiksel olarak uzaysal konumuna bağlı olarak değerlendirilmesini amaçlamaktadır. $\mathrm{Bu}$ çalışmada da noktasal verilerden elde edilen veriler kullanılarak Uzunköprü ilçesi topraklarının mikro element bakımından geneli bir durumunu ortaya koyma amacıyla jeoistatistiksel modellemeler kullanılmış ve Şekil 2'deki haritalar elde edilmiştir.

Bakır dağılım haritalarına bakıldığında Uzunköprü ilçe merkezinin batı, kuzey ve güney kesimlerinde orta ve yüksek değerler görülmektedir. Özellikle Yeniköy’ün batısında bulunan 3 ve 18 numaralı örnekleme alanlarında, Çobanpınarı'nın batısında bulunan 5 ve 6 nolu örnekleme alanlarında ve Karapınar-Türkobası-Kadıköy üçgeninin ortasında yer alan 8 numaralı örnekleme alanında en yüksek değerlere ulaşmaktadır. Ancak bu yüksek değer toksisite yapacak düzeylere ulaşmamaktadır. Uzunköprü ilçe merkezi ve doğusunda ise en düşük $\mathrm{Cu}$ değerleri görülmektedir.

Demir dağılım haritaları incelendiğinde ise, Uzunköprü ilçesinin güneydoğusunda bulunan 14 ve 15 numaralı örnekleme alanlarında en yüksek demir içeriğine sahip olan toprakların olduğu belirlenmiştir. Ancak bu yüksek değerler bitki açısından olumsuz etki yaratabilecek düzeye çıkmamaktadır. Yarayışlı demir içeriklerine birçok 

toprak faktörü etki etmektedir. Özellikle toprakların kireç içerikleri, $\mathrm{pH}$, organik madde, tekstür ve bitki besin elementleri arasındaki antogonistik ilişkiler başta olmak üzere birçok faktör sayılabilir (Adiloğlu, 2007).

Mangan dağılım haritaları ise, Uzunköprü ilçesinin güneybatısında bulunan İpsala sınırına yakın 24 ve 25 numaralı örnekleme alanlarındaki topraklarda mangan düzeyinin yüksek olduğunu göstermektedir. Benzer şekilde Uzunköprü ilçesinin kuzeybatısında bulunan Çakmak köyü kuzeyinde bulunan 10 numaralı örnekleme alanı çevresinde bulunan arazilerde de mangan düzeyinin yüksek olduğu görülmüştür. Bunlara karşın 16, 17, 20 ve 21 numaralı örnekleme alanlarında bulunan topraklar ise en düşük mangan değerlerine sahiptir. Örnekleme noktalarında özellikle 25 numaralı örnekleme noktasından elde edilen mangan değeri literatüre göre de fazla mangan içeren topraklar içerisinde değerlendirilmiştir. Yarayışlı mangan içeriklerinin dağılım haritasına bakıldığında (Şekil 2) görüldüğü üzere mangan içerikleri yetersiz olması topoğrafik yapı, yöney, toprakların kil miktarı ve kil içerikleri, uygulanan tarım desenleri gibi parametreler sebep olabilmektedir (Bağdatlı ve ark., 2018).

Çinko dağılım haritaları ise demir dağılım haritaları ile hemen hemen benzer özellik göstermektedir. 14 ve 15 numaralı örneklemenin yapıldığı Uzunköprü ilçesinin güneydoğusu çinkonun yüksek olduğu alanları işaret etmektedir. Özellikle 14 numaralı örnekleme noktası $1.44 \mathrm{mg} \mathrm{kg}^{-1}$ ile en yüksek çinko düzeyine sahip olan örnekleme noktasıdır. Ancak tüm alana bakıldığında çinko düzeyi toksik etki yaratabilecek düzeyde bulunmamaktadır.
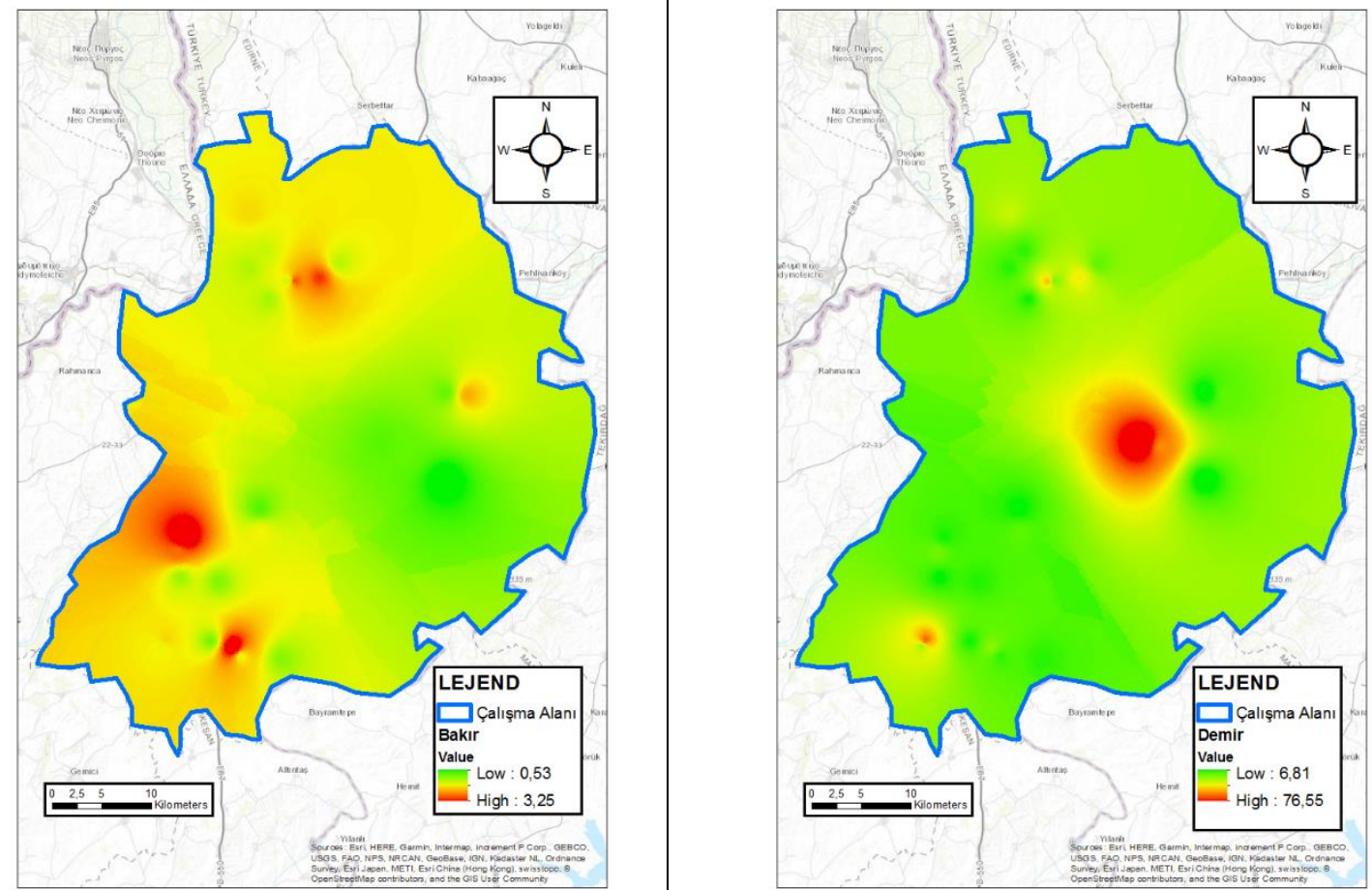

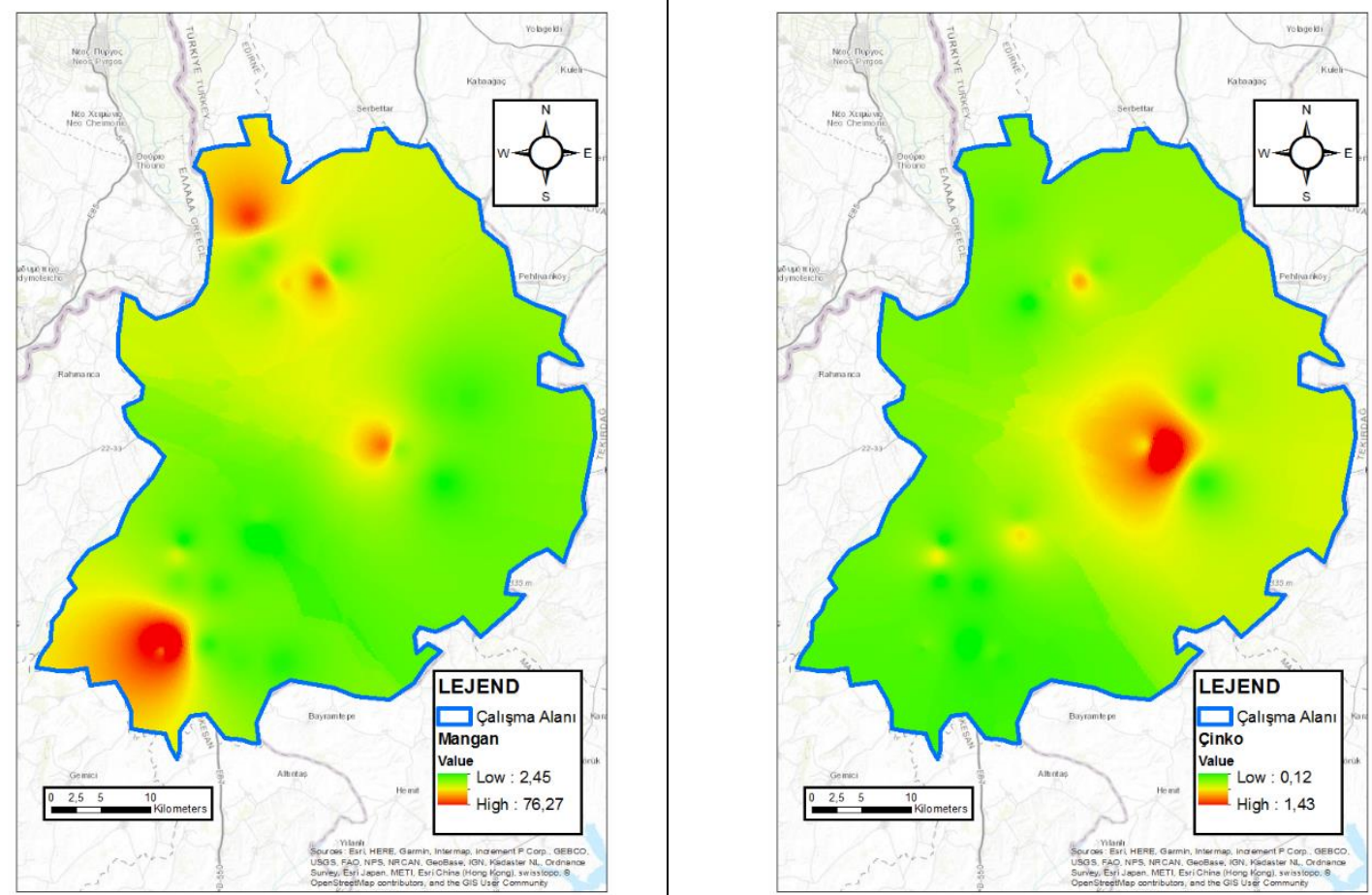

Sekil 2. $\mathrm{Cu}, \mathrm{Fe}, \mathrm{Mn}$ ve Zn dağllım haritalar

Figure 2. $\mathrm{Cu}, \mathrm{Fe}, \mathrm{Mn}$ and $\mathrm{Zn}$ distribution maps

$\mathrm{Bu}$ çalışmada ele alınan mikro besin elementlerinden $\mathrm{Cu}$ ve Fe'nin toprakta literatürde belirtilen değerlerin üzerinde bulunduğu için yalnızca dağılım haritaları üretilmiş; bulunma düzeylerine göre sınıflandırılma haritaları üretilmemiştir. Mangan ve Çinko için üretilen haritalar ise Şekil 3'de verilmektedir.

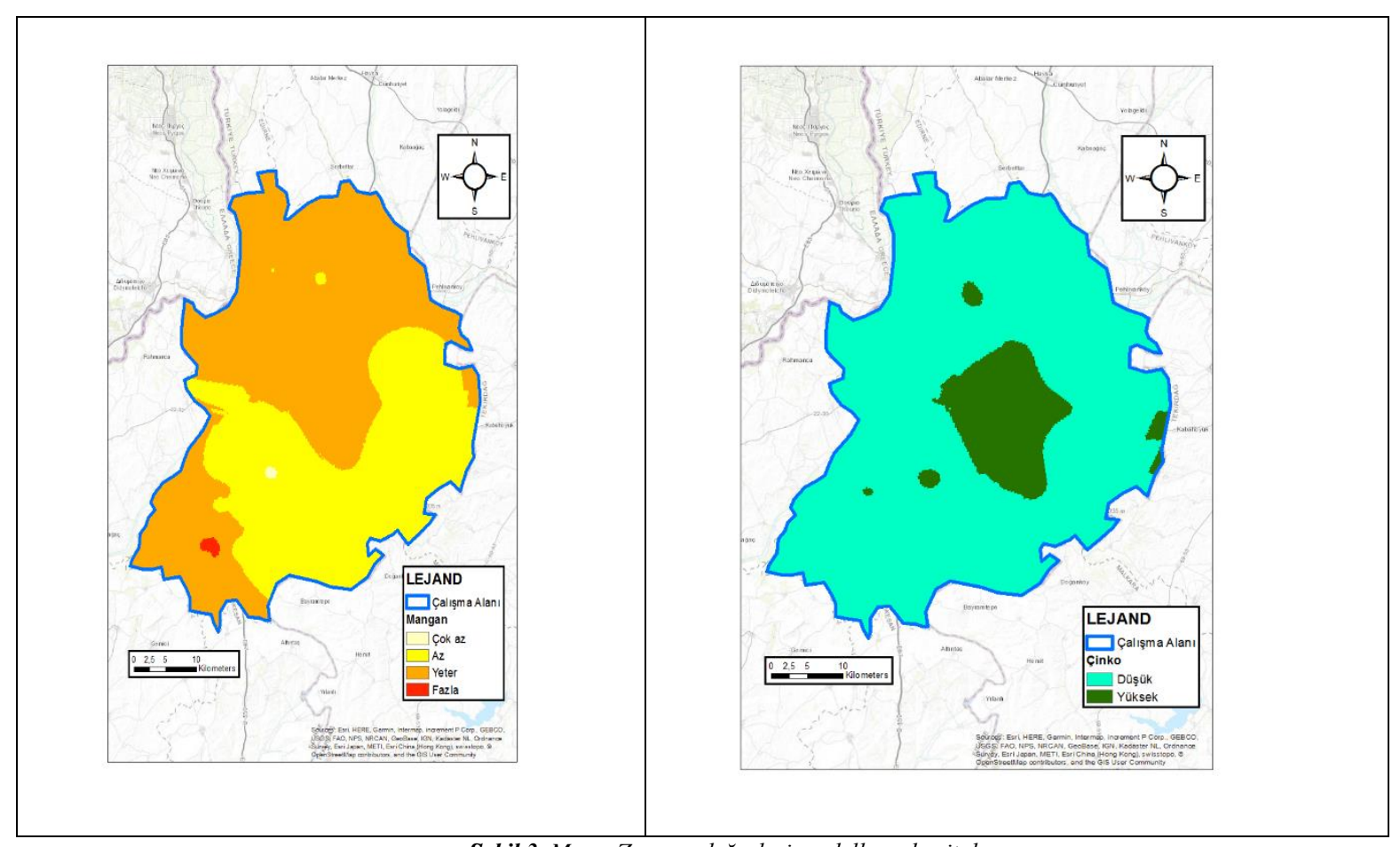

Şekil 3. Mn ve Zn sinır değerleri modelleme haritalart

Figure 3. Modeling maps of Mn and $\mathrm{Zn}$ limit values 

alanı topraklarda çok az, az, yeter ve fazla düzeylerinde belirlenmiştir. Elde edilen haritaya göre çok az ve fazla düzeyde mangan içeren topraklar çok az yer kaplar iken, az ve yeter düzeyde mangan içeren topraklar geniş yer kaplamaktadır. Bölge de benzer şekilde yapılan ağır metal çalışmasında $\mathrm{Cd}$ ve Co gibi ağır metallerin fazla olduğu belirlenmiş̧tir. Aşırı fosforlu gübre uygulamalarının kadmiyum kirliliğine sebep olduğu bilinmektedir. Araştırma topraklarının $\mathrm{Mn}$ ve $\mathrm{Zn}$ içeriklerinin düşük olmasında ağır metal kirliliğinin de etken olduğu düşünülmektedir (Koca ve ark., 2018).

Analiz sonuçlarına göre 0.12 ile $1.44 \mathrm{mg} \mathrm{kg}^{-1}$ arasında değiş̧mekte olan çinko değerlerine ait kritik düzey olarak kabul edilen $0.5 \mathrm{mg} \mathrm{kg}^{-1}$ baz alınarak yapılan çinko haritasında ise çalışma alanında bulunan toprakların büyük bir kısmında çinko noksanlığı olduğu görülmektedir. Bu durum ülkemiz topraklarının \% 50 dünya toprakların da ise \%30 lara varan çinko eksikliği ana materyal, yanlış tarımsal uygulamalar, toprakların fiziksel ve kimyasal özellikleri gibi birçok neden etki etmektedir (Özgüven ve Katkar, 2002; Sungur ve ark., 2012).

\section{Sonuç}

Edirne ili Uzunköprü ilçesi topraklarının bazı mikro element içeriklerinin belirlenmesi ve bunların jeoistatistiksel yöntemlerle modellenmesi amacıyla yapılan bu çalışmada, tesadüfi şekilde alınan 25 adet toprak örneğinin analiz sonuçları değerlendirilmiş̧ir. Bitkiler tarafından daha az miktarlarda kullanılmasından dolayı mikro besin elementi olarak tanımlanan $\mathrm{Fe}, \mathrm{Cu}, \mathrm{Mn}, \mathrm{Zn}$ ve B düzeyleri belirlenmiştir. Mikro besin elementleri içerisinde yeralan $\mathrm{Cu}$ tarımsal arazilerin tamamında yeter düzeyde bulunmuştur. Toprakların Fe içeriği ise genellikle yüksek düzeyde bulunmuştur. Toprakların Mn içeriğine bakıldı̆̆ında ise, toprak örneklerinin \%52'si az ve \%40’’ yeter düzeyde olduğu belirlenmiştir. Tarım arazilerinin $\mathrm{Zn}$ düzeyine bakıldığında ise Türkiye toprakları ile benzerlik göstermekte ve örneklerin önemli bir kısmında Zn kritik düzeyin altında bulunmuştur.

Noktasal verilerin uygun modelleme ile tüm ilçeyi kapsayacak şekilde yapılan jeoistatistiksel yaklaşımda ise elde edilen haritalar ilçe topraklarının mikro element düzeylerinin alansal olarak belirlenmesine de yardımcı olmuştur. Elde edilen haritalara bakıldığında da ilçe sınırlarının tamamında $\mathrm{Cu}$ yeter düzeydedir. Bunun aksine $\mathrm{Zn}$ ise çok önemli düzeyde kritik değerin altında modellenmiştir. Fe ve $\mathrm{Mn}$ ise oldukça değişken olarak değerlendirilmiştir. Elde edilen bu haritalar özellikle tarımsal faaliyetlerde bulunulan alanlarda kısmen de olsa yapılması gereken gübrelemeler hakkında da bilgi verebilmektedir. Özellikle çinkonun düşük olarak haritalandığı bölgelerde üreticilerin mutlak suretle gübre kompozisyonlarına çinko ilave etmeleri gerekliliği ortaya çıkmaktadır. Çalışma alanının hemen hemen tamamında mikro elementler toksik edici düzeylere ulaşmamaktadır. Yalnızca 25 numaralı örneğin alındığı bölgede yüksek düzeyde mangan bulunduğu tespit edilmiştir.

Mikro bitki besin maddesi olan demir bakır çinko ve mangan aynı zamanda bir ağır metaldirler. Bu elementlerin eksikliği durumunda sürdürülebilir tarımdan bahsetmek mümkün olamamaktadır. Birim alandan optimum düzeyde ürün alınması için eksikliğin mutlaka giderilmesi gerekmektedir. Bunun içinde Trakya Bölgesinde toprakların günden güne azalan organik madde içeriklerinin artırılması için organik kaynaklı gübrelerin kullanımının yaygınlaştırılmalıdır. Diğer yandan bu elementlerin yüksek düzeyde varlığı toprak ve bitkiler için kirletici olup bitkisel üretimde toksisiteye neden olmaktadır. Bu kapsamda değerlendirmeye alınan mangan ve çinko değerleri yüksek olan bölgelerde kirletici kaynakların giderilmesi için hem ekonomik ve hem de uygulanabilir çevre dostu bir yöntem olan fitoremediasyon yönteminin kullanılması önerilmiştir 


\section{Teşekkür}

Bu çalışma NKÜBAP tarafından NKUBAP.03.YL.16.045 numaralı proje ile desteklenmiştir. Bu çalışmada kullanılan toprak verileri söz konusu proje kapsamında tamamlanan Danışmanlığı Doç. Dr. Sevinç ADİLOĞLU tarafından yapılan Yüksek Lisans Tezinden alınmıştır. 


\section{Kaynakça/References}

Adiloğlu, A. (2010). The Effect of Zinc (Zn) Application on the Available Iron Contents of Calcereous Soils in Thrace Region, Archives of Agronomy and Soil Science, 49:283-287.

Adiloğlu, A., Adiloğlu, S., Esin, G., Nurettin, Ö. (2010). The Effect of Various Nitrogen Fertilizers on Zinc (Zn) Availability in Non Calcic Brown Forest Soils, Archives of Agronomy and Soil Science, 50:601-606.

Adiloğlu, S. (2007). The Effect of Increasing Nitrogen and Zinc Doses on the Iron, Copper and Manganese Contents of Maize Plant in Calcareous and Zinc Deficient Soils, Agrochimica, 50:114-120.

Adiloğlu, S., Derin, A. (2019). Edirne İli Uzunköprü İlçesinde Yetiştirilen Ayçiçeği (Helianthus Annuus L.) Bitkisinin Bazı Makro Besin Elementi İçeriklerinin Belirlenmesi. Journal of Tekirdağ Agricultural Faculty, 16(1):1-10.

Bağdatlı, M. C., Doran, İ., Adiloğlu, S., Bellitürk, K., Adiloğlu, A. (2018). The Determination of Temporal Change in Land Using with Satellite Images (spot-5,6) in Bilecik Province of Turkey, Advances in Plants Agriculture Research, 8:159-165,

Bellitürk, K. (2011). Edirne İli Uzunköprü İlçesi Tarım Topraklarının Beslenme Durumlarının Belirlenmesi. Tekirdağ Ziraat Fakültesi Dergisi, 8(3): 8-15, Tekirdă̆.

Çakmak, İ., Torun, B., Erenoğlu, E.B., Kalaycı, M., Yılmaz, A., Ekiz, H., Barut H. (1996). Türkiye'de Toprak ve Bitkilerde Çinko Eksikliği ve Bitkilerin Çinko Eksikliğine Dayanıklılık Mekanizmaları. Turkey Journal of Agriculture and Forestry, 20:13-23.

Eyüpoğlu, F., Kurucu, N., Talaz, S. (1996). Türkiye Topraklarının Bitkiye Yarayışlı Bazı Mikro Element Bakımından Genel Durumu. Toprak Gübre Araștırma Enstitüsü Genel Yayın No: 217, Seri No: R-133, Ankara.

FAO. (1990). Micronutrient Assessment at the Country Level. An International -Study (Ed. M. Sillanpa), FAO Soil Bulletin 63, Published by FAO, Roma.

Güneș, A., Aktaş, M., İnal, A., Alpaslan, M. (1996). Konya Kapalı Havzası Topraklarının Fiziksel ve Kimyasal Özellikleri. A.Ü.Z.F. Yayın No: 1453; Bilimsel araştırma ve inceleme No: 801 .

Kacar, B., Katkat, V. (2007). Bitki Besleme. Nobel Yayınevi. ISBN: 978-975-591-834-1.

Karbuz, İ. (2016). Uzunköprü’nün İklim Özellikleri. International Journal of Social Science, 49, 359-373.

Katkat, V., Özgümüş, A., Başar, H., Altınel, B. (1994). Bursa Yöresindeki Şeftali Ağaçlarının Demir, Çinko, Bakır ve Mangan ile Beslenme Durumları. Turkish. Journal of Agric. and Forestry, 18: 447-456.

Kızılgöz, İ., Sakin, E., Yetim, S. (2009). Bazaltik Toprakların Ve Üzerinde Yetiştirilen Arpa (Hordeum vulgare L.) Bitkisinin Besin Maddesi Kapsamı. J.Agric.Fac.HR.U., 2009, 13(2): 9-14.

Kızılgöz, İ., Sakin, E., Gürsöz S. (2011). Ovacık Köyü’nde (Şanlıurfa) Yetiştirilen Asma (Vitis vinifera L.) Çeşitlerinin Mineral Beslenme Durumunun Değerlendirilmesi U.Ü. Ziraat Fakültesi Dergisi, 25(1): 1-10

Koca, Y.K., Derin, A., Adiloğlu, S. (2018). Edirne İli Uzunköprü İlçesi Topraklarının Bazı Ağır Metal Düzeylerinin Jeoistatistiksel Modellenmesi. The International Congress of Eurasian Natural Nutrition and Healthy Life. (DOGAL 2018). 12-15 July, Ankara, Turkey. p.190.

Krauskopf, K.B. (1972). Geochemistry of Micronutrients. Micronutrients in Agriculture. Ed. Monvedt, J.J., Giordano, P.M. and Lindsay, W.L., Soil Science Society of America, Madison WI, p:31-33.

Munis, M.M., Sakin E. (2013). Șırnak İli Cizre İlçesi Kurumcu Köyü Topraklarının Verimlilik Durumlarının Belirlenmesi. Türk Doğa ve Fen Dergisi. 2(1):67-71.

Özgüven, N., Katkat, V. (2002). Bursa İli Topraklarının Bitkiye Yarayışlı Çinko Yönünden Genel Durumu. Uludağ Üniversitesi Ziraat Fakültesi Dergisi 16:235-244.

Sillanpaa, M., Vlek, P.L.G. (1985). Micronutrients and the Agroecelogy of Tropical and Mediterranean Regions. Fert. Res. 7:151-167.

Sungur, A., Adiloğlu, S., Koca, K., Özcan, H. (2012). The Status and Spatial Variability of Some Available Micronutrient in the EzineBayramic Plain Soils. 8th International Soil Science Congress on "Land Degradation and Challenges in Sustainable Soil Management" 15-17 May, Çeșme-İzmir-Turkey, p:519- 524.

Webster, R., Oliver, M.A. (1990). Statistical Method in Soil and Land Resources Survey. Oxford University Press. 